\title{
Plásticos y microplasticos en agua, un problema mundial que afecta nuestros sistemas acuáticos
}

El termino"microplástico" fue elegido como palabra del año 2018 en la Fundéu BBVA y está sirviendo para entender mejor la problemática actual que esto supone. Investigaciones recientes calculan que cada año vertemos al mar más de ocho millones de toneladas de plástico, que representan un peligro para la vida de los animales marinos. La presencia de estas microesferas en el océano está aumentando. La ONU declaró en 2017 que hay hasta 51.000 millones de partículas microplásticas en el mar, 500 veces más que el número de estrellas de nuestra galaxia. Los microplásticos encontrados en el mar pueden ser ingeridos por animales marinos. El plástico se acumula en su cuerpo y puede terminar en los humanos a través de la cadena alimenticia.

En los últimos años ha aumentado la preocupación sobre este tema principalmente por el aumento significativo estas partículas en las zonas costeras y en gran parte del océano pacifico. Los plásticos de gran tamaño terminan en el fondo de los ríos o mares y otros flotan en la superficie siendo en muchos casos consumidos por los animales marinos con los problemas que esto supone. Existe otro foco de contaminación menos visible y que está relacionado con las partículas de plástico que miden menos de un milímetro y que son consideradas como microplásticos. Estas partículas se producen por la propia degradación de los plásticos, desprendimiento de fibras durante el lavado textil o por la utilización en productos de uso cotidiano, como el caso de las cremas exfoliantes que contienen pequeñas esferas de plásticos.

En términos generales, Los plásticos son polímeros orgánicos sintéticos que se forman por la polimerización de monómeros extraídos del petróleo. La principal característica que hace este material atractivo para el ser humano es su durabilidad, a la vez es también su mayor problema ya que es extremadamente resistente a su degradación. Se estima que el polipropileno, un tipo de plástico que se usa habitualmente, como por ejemplo en los tapones de botellas o en los envases de yogurt, puede tardar de 100 a 300 años en degradarse de manera natural. Respecto a otros tipos de plásticos, como por ejemplo el PET (Tereftalato de polietileno) que se encuentra en botellas o el PVC (Policloruro de vinilo) que se puede encontrar en tubos y cañerías entre otros, pueden llegar a tardar hasta 1.000 años. Las bolsas de plástico que utilizamos cada día necesitan unos 150 años para degradarse, mientras que las botellas de plástico podrían necesitar un mínimo de 450 años.

Para sensibilizar sobre la importancia del problema y la urgencia de encontrar soluciones, se invita a la población en general a tomar conciencia y desarrollar estrategias que permitan minimizar este grave problema ambiental que estamos provocando.

Javier Eduardo Sánchez Ramírez

PhD. Ingeniería Química, ambiental y de procesos

Investigador DAM 